Article

\title{
\#MeToo, Sexual Harassment and Coping Strategies in Norwegian Newsrooms
}

\author{
Trond Idås ${ }^{1, *}$, Kristin Skare Orgeret ${ }^{2}$ and Klas Backholm ${ }^{3}$ \\ ${ }^{1}$ Norwegian Union of Journalists, 0186 Oslo, Norway; E-Mail: trond.idaas@nj.no \\ 2 Department of Journalism and Media Studies, Oslo Metropolitan University, 0130 Oslo, Norway; \\ E-Mail: kristin.orgeret@oslomet.no \\ 3 Political Science with Mass Communication, Åbo Akademi University, FI-65101 Vaasa, Finland; \\ E-Mail: klas.backholm@abo.fi \\ * Corresponding author
}

Submitted: 30 September 2019 | Accepted: 15 December 2019 | Published: 25 February 2020

\begin{abstract}
This article, through conducting a study of the sexual harassment (SH) of media workers, investigates the extent and types of $\mathrm{SH}$ experienced by the editorial staff of Norwegian newsrooms at the time the \#MeToo campaign arrived in Norway, and what effects such experiences have on journalists' professional lives. We are also interested in what Norwegian media houses are doing to address these challenges. The leading research question consists of three interrelated parts: To what extent are journalists exposed to SH? What coping strategies do they use? How can newsrooms be better prepared to fight $\mathrm{SH}$, from the perspective of the safety of journalists? A mixed methods approach, which combines findings from a quantitative questionnaire with qualitative in-depth interviews, was used to answer these questions. The findings show that female, young, and temporary media workers are significantly more frequently targeted than others and that those who had experienced SH handled the situation using avoiding strategies to a significantly greater extent than those who had only been exposed to unwanted attention experiences. The findings feed into a discussion of what strategies media houses can use to be better prepared in the fight against $\mathrm{SH}$.
\end{abstract}

\section{Keywords}

coping strategies; female journalists; journalism; newsrooms; safety; sexual harassment

Issue

This article is part of the issue "Rethinking Safety of Journalists" edited by Kristin Skare Orgeret (Oslo Metropolitan University, Norway) and William Tayeebwa (University of Makerere, Uganda).

(C) 2020 by the authors; licensee Cogitatio (Lisbon, Portugal). This article is licensed under a Creative Commons Attribution 4.0 International License (CC BY).

\section{Introduction}

On October 15, 2017, actor Alyssa Milano, in a tweet, urged all women who had experienced sexual harassment $(\mathrm{SH})$ to use the hashtag \#MeToo in social media. In the next few days, the \#MeToo movement was born by millions of women worldwide sharing their stories using this hashtag. In Norway, many were surprised by the extent of $\mathrm{SH}$ in what is often considered to be one of the most gender equal countries in the world. \#MeToo cases relate to $\mathrm{SH}$ and abuse cases in asymmet- ric power relations, for example between employer and employee. The \#MeToo campaign brought about a radical change of norms, with societies through \#MeToo starting to see $\mathrm{SH}$ as a structural problem that needed to be taken seriously. The research on $\mathrm{SH}$ has also escalated in the wake of the campaign, with studies investigating the impact of \#MeToo from the feminist, sociological, journalistic, legal, and medical perspective, including the impact on mental health outcomes (see e.g., Rees, Simpson, McCormack, Moussa, \& Amanatidis, 2019; Wexler, Robbennolt, \& Murphy, 2019). 
The Norwegian media was a key player in the dissemination of information about the \#MeToo campaign. The media is, however, at the same time made up of institutions and workplaces that are at times characterized by asymmetrical power relations. In this article, we investigate the consequences of $\mathrm{SH}$ at work on media workers from a psychological/mental health perspective. This is the first Norwegian study that focuses specifically on the $\mathrm{SH}$ of media workers.

\section{SH and Coping Strategies}

$\mathrm{SH}$ is defined as being unwanted sexual attention (UA) that is perceived by the recipient as being offensive, and which exceeds the individual's coping resources or threatens their well-being (Fitzgerald, Swan, \& Magley, 1997; Isdal, 2016). Lack of mutual consent is the element that defines SH. Unequal power relations, difficulties escaping a situation, and repetitive behavior add to the seriousness of a SH situation (Orgeret \& Vike Arnesen, 2019). The definition of $\mathrm{SH}$ covers a wide range of behaviors, these ranging from unwanted comments and sexually charged staring to sexual assault and rape. A common way of systematizing the content of the term is to divide $\mathrm{SH}$ into physical, verbal, and non-verbal. Power is a key concept in this context. Power can be defined as being one person forcing their will upon another regardless of the wishes or interests of the other person (Matthiesen \& Olsen, 2018), the centering of the \#MeToo campaign on $\mathrm{SH}$ as a misuse of power further reflecting this. Such situations are often characterized by a hierarchical relationship of power between the persons involved and contextual factors such as repetitive behavior and low risk of perpetrator consequences (Sletteland \& Helseth, 2018).

The definition of SH is a topic of controversy. It is both a legal and a phenomenological concept: "Whereas legal definitions need to take the legislatures and judicial decisions into account, the phenomenological experience of harassment is determined solely by the experience of the victim" (Nielsen, Bjørkelo, Notelaers, \& Einarsen, 2010, p. 253). SH is prohibited by Norwegian law (Act Relating to Equality and a Prohibition Against Discrimination, 2018). It is, even so, "a primarily psychological experience best understood from a cognitive grounded stress (coping) model rather than from a strictly legal framework" (Fitzgerald et al., 1997, p. 25). $\mathrm{SH}$ may therefore be associated with a reduction in job satisfaction, lower levels of commitment to an organization, withdrawal from work, physical and mental ill health, and symptoms of post-traumatic stress disorder (Willness, Steel, \& Lee, 2007). The explanation that SH, particularly repeated incidences, induces feelings of discomfort that over time may lead to distress, can explain many of these effects (Nielsen \& Einarsen, 2012). The field of research of workplace bullying and harassment has expanded greatly in recent years. So have the number of studies of the long-term detrimental effects of this upon targets' health and well-being (Hogh, Mikkelsen, \&
Hansen, 2012). We, in this study, follow the distinction between levels of SH presented by Matthiesen and Olsen (2018) and distinguish between UA and SH. Matthiesen and Olsen (2018) define UA as being situations that result in negative perceptions, and $\mathrm{SH}$ as being situations which relate to the enforcement of power. UA covers a number of different types of inappropriate behavior in which the perpetrator experiences the attention as good and in which the target experiences this as being negative. An example is receiving unwanted sexual approaches. Where the target manages to cope with the situation by telling the colleague to stop giving this attention, such behavior can be experienced as being unwise or inappropriate without being offensive. If the target does not, however, manage to communicate this, or if the perpetrator continues the behavior despite negative feedback, then there is a risk that the target's self-esteem will be harmed, which may result in a feeling of being sexually harassed, humiliated, and victimized (Matthiesen \& Olsen, 2018). The seriousness of the harassment is, of course, closely related to the targeted person's interpretation of the experience. This interpretation may also be closely related to her or his vulnerability, which in turn may be affected by, for example, previous experiences of sexual abuse or/and harassment (Kleppe \& Røyseng, 2016; Nielsen et al., 2010).

The severity and manifestation of personal reactions are, furthermore, closely related to the targeted person's coping strategy. Coping is a widely used term in psychology and "refers to attempts to neutralize stress, or as any action that protects people from being psychologically or emotionally harmed" (Scarduzio, Sheff, \& Smith, 2018). Coping strategies are often divided into two major types: problem-focused and emotion-focused. Emotion-focused coping involves managing the emotional responses to stressful situations. Problem-focused coping involves taking control of the stressor, for example removing the source of the stress or removing oneself from the stressful situation. One way of removing a stress source is to report the harassment to the target's company, and letting the company solve the problem. Leaving the company or the department in which the perpetrator works is also a way of removing oneself from a stressor. This is an avoiding coping strategy (Carroll, 2013). Previous research has indicated that SH and UA can have severe negative effects upon both the person targeted and the company, the effects being determined by the coping strategy chosen by the victim. Some coped by reporting the harassment to the company, others left the company (Kleppe \& Røyseng, 2016). Studies have shown that there is a lack of a culture of reporting SH (Benavides-Espinoza \& Cunningham, 2010). The fear of retaliation and of the burden that can follow reporting managers and colleagues for $\mathrm{SH}$ are also common reasons for not acting (Buchanan, Settles, Hall, \& O'Connor, 2014).

Vohlídalová (2015) links the lack of awareness of and reactions to $\mathrm{SH}$ to a gender ideology that actively legit- 
imates SH. She argues that an example of legitimation may be the tendency to trivialize and belittle $\mathrm{SH}$ and its impact on targets, to prevent forms of behavior that are legally defined as being SH being defined as such. This is further reflected in the tendency to shift the solution of $\mathrm{SH}$ from the institutional (i.e., organization action) to the individual level, an important aim of the \#MeToo movement being to move this focus back from the individual to a structural and institutional level. The increasing tendency of seeing these threats to women in newsrooms as a safety issue is also part of a trend focusing more on a structural level than on the individual one only. Furthermore, Nadine Hoffman, the Deputy Director of the International Women's Media Foundation, stresses the importance of not dismissing $\mathrm{SH}$ as a workplace or human resources issue. She instead argues that $\mathrm{SH}$ must be treated as a safety issue and be taken as seriously as the dangers of reporting from hazardous locations and being targeted because of the coverage of an organization or an issue. She also states that if these issues are not addressed, then the impact will go beyond those involved leaving the industry out of frustration or concern for their safety (Hoffman, as cited in Young, 2019).

\section{The Norwegian Scene}

Norway has a well-organized work environment. Tariffs and working conditions are regulated by national and local collective agreements between employer organizations and the trade unions. This includes the media sector. Around $90 \%$ of the 9000 or so professional journalists in Norway are members of The Norwegian Union of Journalists (NJ). One out of ten journalists are freelancers, the remainder being temporary or staff employees. Around $45 \%$ of journalists are women. Most editors are members of The Association of Norwegian Editors (NR), which has around 800 members, one third being women (NJ, 2018; NR, 2019). The Norwegian Broadcasting Corporation (NRK), Norway's public service broadcaster, has 3000 employees and is the largest media company in Norway. Around 1700 NRK employees are NJ members. The commercial television broadcaster TV2 is the second largest media house in Norway and has around 750 employees, 340 being NJ members. The next media houses ranked by size are the traditional newspaper houses of Schibsted, Amedia, and Polaris Media. These own around $70 \%$ of the 225 local, regional and national media houses (Norwegian Audit Bureau of Circulations, 2019; Norwegian Media Authority, 2019). The daily media consumption per inhabitant in Norway is, for a country with a population of less than 5 million, one of the highest in the world (Statistics Norway, 2019).

Employer and employee organizations in the media sector have cooperated since 1980 to conduct of a number of national surveys on working conditions. Harassment, threats, and violence were major issues for editors and journalists in the 2012 survey. However, the inclusion of $\mathrm{SH}$ in newsrooms in the questionnaire was not even thought about until the \#MeToo campaign hit Norwegian media companies, the campaign impacting this sector as hard as other parts of working life. Media organizations responded by launching a web-based survey in 2017. All media employees were invited to participate in this national investigation of $\mathrm{SH}$ in the media sector.

The primary goal of the \#MeToo campaign was to uncover $\mathrm{SH}$ in the workplace that is characterized by asynchronous power relations. This type of hierarchical power can emerge in the media sector between managers or other superiors and journalists, particularly between superiors and temporary workers. Media organizations have undergone a considerable number of reorganizations and staff downsizing rounds in recent years, the use of temporary workers consequently increasing (Grimsmo \& Heen, 2013). This provides an additional reason for looking into this issue. The survey also focused on differences due to gender, age, and employment status. How targets/victims cope with unwanted attention was also a topic of investigation. The survey therefore also examines the extent to which different demographic groups chose an offensive strategy of reporting harassment to the company, or a defensive coping strategy of avoiding the perpetrator.

The major findings of the survey describe the extent of $\mathrm{SH}$ and UA in media companies and were presented in December 2017 (NJ, 2017). The survey revealed that $4 \%$ of journalists and editors had experienced $\mathrm{SH}$ in the previous six months, while $23 \%$ had experienced at least one type of UA at work in the same time period. One out of five cases were, furthermore, typical \#MeToo cases in which the perpetrator was a company superior. The percentage rates for $\mathrm{SH}$ reported in these finding may be considered to be low. They are, however, four times higher than those recorded in a similar study of Norwegian working life in general (Nielsen et al., 2010). Media organizations followed up the results by implementing concrete action plans that were aimed at changing attitudes to and sharpening awareness of $\mathrm{SH}$.

Little attention was, however, given to the coping strategies of targeted journalists in the initial data analysis, and in subsequent debates and implemented actions. Coping strategies, however, represent a major issue. We therefore decided to carry out a separate analysis of those who reported harassment to their company and those who chose an avoiding strategy. The first analysis showed only $14 \%$ of SH incidents were reported to media houses (Idås \& Backholm, in press). Female journalists reported more frequently than male colleagues. $\mathrm{SH}$ that involved superiors (the \#MeToo cases) was reported less often than cases that involved other colleagues. The most common reason for not reporting was that the targeted person did not consider the incident to be serious enough to be reported. The second most common reason for not reporting was the fear of consequences/retaliation (Idås \& Backholm, in press).

In this study we will, however, investigate the issues of $\mathrm{SH}$ and coping strategies in more detail and explore 
how Norwegian media houses address these challenges. We in particular investigate media workers who chose a defensive coping strategy (avoidance), by both looking into demographics (gender, age, and employment) and by investigating whether the perpetrator's position in a media house influenced the target's coping strategy. The leading research question therefore consists of three interrelated parts: To what extent are journalists exposed to $\mathrm{SH}$ ? What coping strategies do they use? How can newsrooms be better prepared to fight $\mathrm{SH}$, from the perspective of safety of journalists?

\section{Methods}

A mixed methods approach was used to investigate the three interrelated research questions. The first part of the article presents findings from a quantitative questionnaire survey of Norwegian journalists and editors. The second part discusses aspects of these findings through qualitative in-depth interviews with editors and journalists who covered the \#MeToo campaign in Norwegian media houses. The two methods were therefore employed sequentially, findings from the survey informing the qualitative interviews.

\subsection{Participants and Procedures}

The questionnaire for this study was launched in November 2017, just a few weeks after the \#MeToo campaign arrived in Norway. It was distributed by email to all working members of NJ $(n=6303)$ and NR $(n=730)$. A total of 3626 journalists and editors responded. The respondents were asked whether they were members of the NJ or the NR. The 3143 respondents who stated they were a member of NJ were considered in this study to be journalists. The 499 who stated they were a member of NR were considered to be editors. The response rate was $50 \%$ for NJ members and $68 \%$ for NR members (see Table 1).

We furthermore selected 12 interviewees from six major Norwegian media houses for qualitative in-depth interviews. The media houses were chosen to provide a mix of national and regional houses, and different types of ownership. The interviewees were purposively selected. All had covered the \#MeToo campaign. This was not a necessity for being able to say something about how newsrooms could be better prepared to fight $\mathrm{SH}$. This subgroup was, however, chosen because discussing $\mathrm{SH}$ with journalists who had covered issues relating to misuse of power, UA, and SH in the light of the \#MeToo campaign, could provide a more nuanced content. Some of the interviewees had answered the quantitative questionnaire. This was not, however, a precondition for being selected. The interviews lasted between 30 and 45 minutes and were carried out at the media houses in Bergen and Oslo. They were semi-structured. We followed an interview guide to ensure we obtained answers to the same questions from all interviewees. We also pursued the particularities of each interview. The interviews took place between May and October 2018. They were recorded and later transcribed. We were particularly interested in using the qualitative interviews to obtain comments on the quantitative findings and answers to the third research question, which is how newsrooms can be better prepared to fight $\mathrm{SH}$.

\subsection{The Questionnaire: Measures}

The questionnaire was constructed by taking items from other Norwegian studies on $\mathrm{SH}$, and by developing a number of items specifically for this study. The Bergen SH Scale (BSHS) has been used to measure SH and UA (Einarsen \& Sørum, 1996). BSHS is a validated scale and has been used in a number of studies on SH in Norwegian working life (Kleppe \& Røyseng, 2016; Nielsen et al., 2010). Using BSHS in this study allows the results of the \#MeToo survey to be compared with other studies. The scale consists of two parts. Part 1 measures exposure to UA using an inventory of 11 items that assess the following types of $\mathrm{SH}$ : unwanted verbal sexual attention, unwanted physical sexual behavior, and sexual pressure. The respondents were asked how often they had been exposed to each behavior in their present workplace or at a work-related social event in the last six months. Response choices were: $0=$ Never; $1=$ Once; $2=2-5$ times; 3 = More than 5 times; $4=1$ don't know; and $5=$ I don't want to answer. A sum score was calculated for those who responded 0-3 for each of the eleven questions, giving a possible range for the sum score of 0-33 $(n=3226)$. Those responding 4 or 5 were excluded from the analysis. The items showed satisfactory internal consistency in this study (Cronbach's $\alpha=0.71$ ). Part 2 asks whether the respondent had been exposed to $\mathrm{SH}$ at work in the last six months, without a concise definition of $\mathrm{SH}$ being presented. The response alternatives were: $0=\mathrm{No}$; 1 = Yes; 2 = I don't know; and 3 = I don't want to answer. The data from those responding 0 or 1 were used ( $n=3591)$.

Table 1. Demographic data.

\begin{tabular}{lccc}
\hline Member of & NJ $n=3144$ & NR $n=499$ & Total $n=3627$ \\
\hline Female & $52 \%$ & $33 \%$ & $49 \%$ \\
Age & \pm 43 years & \pm 48 years & \pm 44 years \\
Staff employees & $82 \%$ & $99 \%$ & $85 \%$ \\
Temporary employees & $9 \%$ & $0.4 \%$ & $8 \%$ \\
Freelancers & $9 \%$ & $0 \%$ & $8 \%$ \\
\hline
\end{tabular}




\subsection{Who Was the Perpetrator?}

To investigate the type of perpetrators in \#MeToo cases in SH incidents in Norwegian newsrooms, we asked the question: "Who was behind the harassment or abuse that you were exposed to?" Response alternatives were: 1 = A workplace manager; 2 = A workplace colleague; 3 = Another colleague; $4=$ Another person I met at work; $5=$ Another person; $6=1$ don't know; and $7=1$ don't want to answer. The categories were reconstructed to: 1 = A workplace manager; 2 = A workplace colleague; and $3=$ Another person. 1346 respondents selected one of these alternatives. Alternative 3 consisted of the original categories 3-5.

\subsection{Coping Strategies}

We investigated how respondents coped with SH/UA by using a scale that was developed by the Work Research Institute to study hate speech against Norwegian journalists and editors (Hagen, 2015). Using this scale allows data relating to the harassment/threatening of editorial staff by the public to be compared with journalists/editors who have experienced $\mathrm{SH}$ and/or UA from superiors and colleagues. The question was: "How were you affected by the harassment or abuse?" The scale consists of 13 items that cover the psychological distress and consequences related to what we in this study label "avoidance." The options were: $1=$ I have changed work tasks to less visible ones; 2 = I have thought about quitting $m y$ job; 3 = I have refrained from tasks; and $4=$ I have changed job.

A score was constructed based on these options to indicate the range of avoidance subtypes. The scale was: $0=$ No reactions; $1=$ One type of reaction; $2=$ Two types of reactions; $3=$ Three types of reactions; and $4=$ Four types of reactions (possible range $=0-4 ; n=853$ ). No respondents reported all four types of reactions. A dichotomous variable was also constructed, the response alternatives being $0=$ No and $1=$ Yes (score on at least one of the four alternatives in the original scale).

\subsection{Statistics: Analysis}

Categorical and dichotomous variables were analyzed using Crosstabs and Chi-square tests. Combinations of categorical and continuous variables were analyzed using an independent $t$-test and between-groups analysis of variance (ANOVA).

Three demographic groups were used in the study: gender; age; and type of employment (Table 1). All were dichotomized. Age was dichotomized into $0<36$ years ( $n=927)$ and $1 \geq 36$ years $(n=2699)$ and employment into $0=$ Temporary employees $(n=288)$ and $1=$ Staff employees $(n=3045)$. The 22 respondents who answered "I don't know" and the 271 respondents who responded "Freelancer" were not included in the analysis, as it can be argued that they are not a part of the day-to-day life of the newsrooms.

A categorical scale was constructed to analyze the differences between those who had experienced harassment: $0=$ No harassment $(n=2773) ; 1=$ Solely UA experiences $(n=716)$; and $2=\mathrm{SH}$ experiences $(n=137)$. Another categorical scale was created to investigate differences between those who had never previously experienced harassment ( $0=$ No harassment; $n=2773$ ) and those who had at least one experience of $\mathrm{UA}$ or $\mathrm{SH}$ (1 = UA/SH; $n=853)$.

\section{Results: The Questionnaire}

We present here the main findings and results from the first part of the study (the questionnaire). The results of the frequency analysis are presented in Tables 1-7. Percentages are rounded to the nearest whole number.

3592 respondents responded to the single-item question about SH. Of these, 137 (4\%) claimed that they had been exposed to $\mathrm{SH}$ at work in the last six months, 97 of these (71\%) being "in-house," and involving 29 managers (22\%) or 68 colleagues (50\%). The perpetrator was someone else in 40 of the cases (29\%). Frequency analysis indicates that female journalists had been more frequently exposed to $\mathrm{SH}$ by managers or colleagues than male journalists/editors (Table 2). Journalists younger than 36 had been more frequently exposed to $\mathrm{SH}$ than colleagues

Table 2. Frequency of experienced SH in last six months.

\begin{tabular}{lcccc}
\hline Role of perpetrator: & All & Manager & Colleague & Others \\
\hline All $n=3591$ & $4 \%$ & $1 \%$ & $2 \%$ & $1 \%$ \\
Female $n=1753$ & $7 \%$ & $1 \%$ & $3 \%$ & $2 \%$ \\
Male $n=1838$ & $1 \%$ & $0 \%$ & $1 \%$ & $0 \%$ \\
$<36$ years $n=910$ & $8 \%$ & $1 \%$ & $4 \%$ & $2 \%$ \\
$>36$ years $n=2681$ & $3 \%$ & $1 \%$ & $1 \%$ & $1 \%$ \\
Temporary $n=284$ & $10 \%$ & $1 \%$ & $7 \%$ & $1 \%$ \\
Staff employee $n=3023$ & $3 \%$ & $1 \%$ & $1 \%$ & $1 \%$ \\
\hline
\end{tabular}

Notes: A Chi-square-test indicated that there was a significant difference between the sexes for $\mathrm{SH}: \chi^{2}(1, n=3225)=61.24, \mathrm{p}<0.001$. This test also indicated a significant difference in SH scores between the age groups, $\chi^{2}(1, n=3225)=42.13, p<0.001$, and between temporary and staff employees, $\chi^{2}(1, n=2993)=33.34, \mathrm{p}<0.001$. 
$\geq 36$ years, and temporary workers more frequently exposed to SH than staff employees.

\subsection{UA}

Almost one in four respondents (23\%) reported having been exposed to at least one type of UA at work in the last six months. Of the 843 editors and journalists who had been exposed to UA, 454 (54\%) had experienced more than one of the 11 types included in the survey, while 557 (66\%) had experienced one of the types more than once in the last six months.

The scores for the different types of UA are presented in Table 3. The survey indicates that "Unwanted comments with a sexual content" and "Unwanted comments about clothing, body, or way of living" were the two most frequently reported types of harassment. "Unwanted requests/demands for sexual services with the promise of rewards," "Unwanted requests/demands for sexual services with threats of punishment or sanctions," and "Sexual assault, attempted rape, or actual rape" were the least reported types of harassment.
Of the 843 reported incidents of UA, 485 (58\%) occurred in-house. A manager was involved in 89 (18\%) of these cases, a colleague being involved in the remaining 346 (82\%) of in-house cases. The results presented in Table 4 indicate that female journalists were more frequently exposed to UA than male colleagues, that those below 36 years were more frequently exposed than older colleagues, and that temporary employees experienced UA more frequently than members of staff.

An independent-samples t-test was conducted to compare the UA scores for female and male journalists/editors. There was a significant difference between the female and male scores $(M=1.07, S D=2.29$ vs. $M=0.33, S D=1.18$; $\mathrm{t} 2245.37]=11.38, \mathrm{p}<0.001)$. This test on age groups also indicated that there was also a significant difference between respondents below 36 years and those $\geq 36$ years $(M=1.12, S D=2.29$ vs. $M=0.54$, $S D=1.62 ; \mathrm{t}[1095.60]=7.79, \mathrm{p}<0.001)$. A t-test for significant differences in UA-scores also showed a significant difference between the scores of temporary employees and staff employees $(M=1.03, S D=2.14$ vs. $M=0.63, S D=1.73 ; \mathrm{t}[272.24]=3.69, \mathrm{p}<0.001)$.

Table 3. Frequency of UA in last six months (split on 11 items).

\begin{tabular}{|c|c|c|c|c|}
\hline Have you experienced & Never & Once & $2-5$ times & $>5$ times \\
\hline Unwanted comments about clothing, or body, or way of living ( $n=3558$ ) & $88 \%$ & $5 \%$ & $5 \%$ & $1 \%$ \\
\hline Other unwanted verbal comments with sexual content $(n=3516)$ & $86 \%$ & $5 \%$ & $7 \%$ & $3 \%$ \\
\hline $\begin{array}{l}\text { Pictures or objects with sexual content, which you experienced as } \\
\text { undesirable or unpleasant }(n=3583)\end{array}$ & $98 \%$ & $2 \%$ & $1 \%$ & $0.1 \%$ \\
\hline Being the object of rumors with a sexual content $(n=3436)$ & $97 \%$ & $2 \%$ & $1 \%$ & $0.1 \%$ \\
\hline Sexually charged staring or glances, which felt uncomfortable $(n=3506)$ & $93 \%$ & $2 \%$ & $3 \%$ & $1 \%$ \\
\hline Unwanted telephone calls or letters with sexual content $(n=3610)$ & $98 \%$ & $1 \%$ & $1 \%$ & $1 \%$ \\
\hline Unwanted physical contact with sexual suggestions $(n=3592)$ & $93 \%$ & $4 \%$ & $2 \%$ & $0.3 \%$ \\
\hline $\begin{array}{l}\text { Unwanted sexual approaches that you experienced as uncomfortable, } \\
\text { but which did not contain promises of rewards or threats of } \\
\text { punishments or sanctions ( } n=3595)\end{array}$ & $97 \%$ & $2 \%$ & $1 \%$ & $0.1 \%$ \\
\hline $\begin{array}{l}\text { Unwanted requests/demands for sexual services with a promise } \\
\text { of rewards }(n=3614)\end{array}$ & $99.7 \%$ & $0.1 \%$ & $0.1 \%$ & $0.1 \%$ \\
\hline $\begin{array}{l}\text { Unwanted requests/demands for sexual services with threats of } \\
\text { punishment or sanctions }(n=3615)\end{array}$ & $99.7 \%$ & $0.1 \%$ & $0.1 \%$ & $0 \%$ \\
\hline Sexual assaults, attempted rape, or actual rape $(n=3627)$ & $99.9 \%$ & $0.1 \%$ & $0 \%$ & $0 \%$ \\
\hline
\end{tabular}

Table 4. Frequency of UA in last six months (score on at least one item).

\begin{tabular}{lccrr}
\hline Role of perpetrator: & All & Manager & Colleague & Others \\
\hline All $n=3626$ & $23 \%$ & $4 \%$ & $10 \%$ & $6 \%$ \\
Female $n=1777$ & $34 \%$ & $8 \%$ & $17 \%$ & $12 \%$ \\
Male $n=1849$ & $13 \%$ & $2 \%$ & $5 \%$ & $2 \%$ \\
$<36$ years $n=927$ & $35 \%$ & $5 \%$ & $17 \%$ & $13 \%$ \\
$>36$ years $n=2699$ & $19 \%$ & $6 \%$ & $8 \%$ & $7 \%$ \\
Temporary $n=288$ & $37 \%$ & $5 \%$ & $19 \%$ & $12 \%$ \\
Staff employee $n=3045$ & $22 \%$ & $10 \%$ & $7 \%$ \\
\hline
\end{tabular}




\subsection{Harassed by Who?}

The study indicates that $22 \%$ of those who reported SH/UA have been harassed by a manager, $48 \%$ by a colleague, and $31 \%$ by someone outside the company (Table 5). A Chi-square test for independence indicated that there was a significant difference between the age groups and the role of the perpetrator (manager, colleague, or other), $\chi^{2}(2, n=706)=8.37, p=0.015$. Chisquare tests for the other two demographic groups did not indicate significant variations: gender $\chi^{2}(2, n=706)$ $=3.17, \mathrm{p}=0.21$; employment $\chi^{2}(2, n=645)=2.44$, $\mathrm{p}=0.30$.

\subsection{Coping}

Of the 853 who had experienced SH/UA at work, 123 (14\%) reported reactions that can be interpreted as being a desire to avoid the perpetrator. The most typical reaction was considering changing job (7\%), changing job (4\%), or abstaining from duties (5\%). The sum scale for avoidance was higher among those who had experienced $\mathrm{SH}$ than those who had only been exposed to UA experiences (Table 6). A one-way ANOVA analysis of variance indicated a significant variance in avoid- ance between those without SH/UA experience, those who solely had experienced UA and those who had experienced $\mathrm{SH}, F(2,3623)=97.0, p<0.001$. A post-hoc comparison (Tukey HSD test) was used to identify where the differences between the groups occurred. The comparisons indicated that the mean score for the "no harassment" group was significantly different $(p<0.001)$ from that for those who had experienced UA $(M=0.03$, $S D=0.22$ vs. $M=0.16, S D=0.49)$ and $S H(M=0.03$, $S D=0.22$ vs. $M=0.32, S D=0.061)$. The comparison also indicated a significant difference between the avoidance scores of those who had experienced UA or SH $(M=0.16$, $S D=0.49$ vs. $M=0.32, S D=0.061$ ).

A further one-way ANOVA analysis was conducted to explore the impact of the role of the perpetrator (manager, colleague, or other) on the variance in avoidance for respondents who had experienced SH/UA ( $n=853$; Table 7).

The test indicated a significant variance in avoidance for the three perpetrator groups $F(2,703)=8.0$, $p<0.001$. A post-hoc comparison (Tukey HSD test) was used to identify where the differences among the groups occurred. The comparisons indicate that the mean score for those harassed by managers $(M=0.38, S D=0.69$ ) was significantly different from those harassed by col-

Table 5. Harassed by who (SH+UA)?

\begin{tabular}{lccr}
\hline Role of perpetrator & Manager & Colleague & Other \\
\hline All $n=706$ & $22 \%$ & $48 \%$ & $3 \%$ \\
Female $n=548$ & $22 \%$ & $47 \%$ & $32 \%$ \\
Male $n=158$ & $22 \%$ & $53 \%$ & $25 \%$ \\
$<36$ years $n=272$ & $16 \%$ & $52 \%$ & $32 \%$ \\
$>36$ years $n=434$ & $25 \%$ & $45 \%$ & $29 \%$ \\
Temporary employee $n=90$ & $16 \%$ & $53 \%$ & $31 \%$ \\
Staff employee $n=555$ & $23 \%$ & $49 \%$ & $28 \%$ \\
\hline
\end{tabular}

Table 6. Frequency of use of avoiding coping strategy.

\begin{tabular}{lccr}
\hline Type of harassment & SH+UA & SH & UA \\
\hline All $n=853$ & $14 \%$ & $26 \%$ & $12 \%$ \\
Female $n=611$ & $17 \%$ & $28 \%$ & $14 \%$ \\
Male $n=242$ & $7 \%$ & $14 \%$ & $7 \%$ \\
$<36$ years $n=327$ & $16 \%$ & $27 \%$ & $12 \%$ \\
$>36$ years $n=526$ & $14 \%$ & $26 \%$ & $12 \%$ \\
Temporary employee $n=106$ & $13 \%$ & $11 \%$ & $14 \%$ \\
Staff employee $n=671$ & $14 \%$ & $30 \%$ & $11 \%$ \\
\hline
\end{tabular}

Table 7. Avoiding coping strategy and harassed by who?

\begin{tabular}{lcrr}
\hline Role of perpetrator & Manager & Colleague & Other \\
\hline All $n=706$ & $29 \%$ & $15 \%$ & $13 \%$ \\
Female $n=548$ & $31 \%$ & $17 \%$ & $14 \%$ \\
Male $n=158$ & $20 \%$ & $8 \%$ & $8 \%$ \\
Temporary employee $n=90$ & $50 \%$ & $10 \%$ & $7 \%$ \\
Staff employee $n=555$ & $24 \%$ & $15 \%$ & $13 \%$ \\
\hline
\end{tabular}


leagues $(M=0.19, S D=0.50)$ and others $(M=0.16$, $S D=0.49)$. There was no significant difference between the mean scores for avoidance for those harassed by colleagues and others. This indicates that SH/UA by a manager had a significant negative effect on the working relationship. For example, that the journalist left or considered leaving the company because of the manager's behavior. The study did not indicate similar effects if the SH/UA perpetrator was a colleague or someone outside the media house.

\section{Results: Qualitative Interviews}

In this section, we look more closely into how the findings from the questionnaire and the central results from conducted interviews can be used to strengthen media houses in their fight against $\mathrm{SH}$. Neither journalists nor editors are neutral interviewees. They are strategic decision makers who need to justify their conclusions. Nevertheless, the interviews provide interesting insights into aspects of how the safety and well-being of media workers were reflected in newsrooms. We presented to the journalists, during the interviews, the findings that relate to the research question: "To what extent are journalists exposed to SH?" Female media workers are significantly more frequently the target of UA and $\mathrm{SH}$ than their male colleagues. Those aged below 36 are more vulnerable than those above. Temporary employees are more exposed than staff employees. The interviewees expressed that these findings to a great extent reflect their experience of their lived realities within their respective newsrooms. Most of the media workers were, however, surprised at the high figure of $23 \%$ of media workers experiencing one or more unwanted experiences in the last six months:

The findings from the questionnaire research question "What coping strategies do they use?" showed that one of four who had experienced SH coped with the situation through avoiding strategies such as considering a change of job or change of department (Table 6). The findings indicated that those who had experienced $\mathrm{SH}$ handled the situation by using avoiding strategies to a significantly and much greater extent than those with solely experienced unwanted attention. Both of these groups to a much greater extent considered a change of job or had already moved to another employer than those without SH/UA experiences. $11 \%$ had left or considered leaving their job due to $\mathrm{SH}$ or unwanted attention. The interviewees found these numbers "shocking" when presented with them. The numbers indicate that newsrooms with a SH/UA culture are at risk of losing valuable employees. Some said that they saw this as "a wake-up call." (Personal communication, 2018)

The interviewees explained, when discussing how newsrooms can be better prepared to fight $\mathrm{SH}$ from the per- spective of safety of journalists, that their media organization had after \#MeToo evaluated their rules and routines, and that the reporting routines had been evaluated and communicated to all staff members:

Of course, there is a lot we should have done earlier. There is a lot to learn from the \#MeToo campaign....This is not to say that SH was fully accepted previously, but the way we treat it has changed. (Personal communication, 2018)

A number of interviewees explained, when discussing coping strategies, that they knew of someone who had changed their field of work due to $\mathrm{SH}$. A few also said that this was a part of a broader picture that they had not reflected on much until now. One argument that was brought up in the discussions was the need to look at the consequences of the harassment in a socio-economic perspective:

Women have to find new jobs, workplaces need to train new employees. We have to consider this as a problem for the entire workplace culture and for society, not just for the individual. (Personal communication, 2018)

At an almost philosophical level, there were discussions in some newsrooms of "what is not there," or rather of "who is not here," and what this may imply for the quality of journalism:

I've been thinking a lot about it during the \#MeToo campaign. Who we have lost, not necessarily only in our field, but also in the film industry, academia, and in politics. I have talked about writing a story about it. But so far this has not materialized. I have to try to get hold of those who simply quit or could not stand it anymore because of SH. The important voices we lost...it is so sad. It is definitely one of the consequences. (Personal communication, 2018)

Some journalists explained that they had seen the tendency for women to leave the scene due to a "rotten culture." The interviewees also expressed that the support of co-workers and superiors, and a culture of trust and justice, made it easier to stand up to those who harassed:

We should not underestimate the value and the power of the social meeting points in the journalistic and cultural field. These are places where a lot of important exchange takes place, which impact the professional life. It is crucial that everybody feels safe there. (Personal communication, 2018)

The findings also indicated that the SH/UA avoiding effect was significantly stronger among employees who had been harassed by a manager than for those harassed by a colleague at the same level or someone outside 
the company. This tendency was particularly significant among temporary employees, with $50 \%$ of those who had experienced SH/UA by a manager responding that they considered changing or had already changed job. Fear of retaliation was a major reason for not reporting an incident and for choosing an avoiding strategy. The findings indicate that more than one out of five SH/UA cases took place within an asymmetric power relation (Table 5). The ratio of managers to employees is about 1:10 in Norwegian newsrooms (based on the number of members in NJ and NR). Managers are therefore clearly overrepresented as abusers in the statistics.

\section{Conclusion: The Way Forward}

All the interviewed journalists, when discussing how to move forwards and to be better prepared to fight $\mathrm{SH}$ and power abuse, stressed the importance of raising awareness. A good example of this was the editor-in-chief of a leading national newspaper who, in his welcoming address to new temporary summer employees in 2018, stressed the routines for reporting SH. This was the first time such information had been given to interns. This emphasizes the importance of healthy working relationships and of being able to trust your co-workers and superiors. Some, however, felt that a great deal of focus was centered on raising awareness among young media workers, whereas awareness probably most needed raising among the older generation. The need to consider UA and $\mathrm{SH}$ as being a problem of the entire workplace culture, and not just of the individual, was also frequently mentioned in interviews. Some stressed the value of female mentors of a certain age. It was seen to be problematic that female journalists above 30 in many areas became tired of an "unhealthy culture" and avoided social meeting spaces, whereas male colleagues continued year after year. Some furthermore thought finding a balance between the seriousness of power abuse, without demonizing all men, was challenging. The taboo relating to the SH of men was also a topic that deserves more attention ( $15 \%$ of those who experienced $\mathrm{SH}$ in this study, $n=137$, were men). One hypothesis is that the avoidance effect is even higher among men exposed to harassment. We therefore need to acknowledge the barriers that may prevent a man from disclosing his experiences, such as social expectations about what it means to "be a man."

We have seen that the threat of reprisals was the major reason for choosing a defensive strategy to SH. 26\% of respondents who had experienced SH reported that it had impacted their journalistic work. This means that these journalists will make professional decisions based not on journalistic quality, but on protecting themselves. We here see some clear parallels with the concept of selfcensorship in journalism. In this, journalism and the media are driven not by editorial concerns, but by fear. It is commonly argued that there can be no press freedom or independent journalism when fear of retaliation stalks a newsroom (White, 2014).
Suppressing (young, female) voices through $\mathrm{SH}$ is also a way of censoring important contributions to the public sphere. The effect of journalists choosing avoidance, leaving the profession, or choosing beats in which they will be less visible is a loss to media houses and to the public sphere. We have seen how self-censorship operates in relation to journalist security and freedom of expression. We have also seen how, particularly for female journalists, misogynistic attacks can create a chilling effect that silences their voices and creates a deterrent to freedom of expression that ultimately erodes freedom of the press. Preventing SH is closely linked to knowledge and awareness. It is easier to reject the trivialization and belittling of SH when we are aware that such actions exist, and of its impact on targets.

The findings of the questionnaires and the interviews stress the importance of having both a policy and a culture that emphasizes that UA is not tolerated. The findings indicate that newsrooms with a negative social climate and a culture of SH/UA are at risk of creating psychosocial problems, longitudinal consequences, and of losing valuable employees. The potential for strengthening the cohesion and working environment of the editorial staff by implementing a $\mathrm{SH}$ action plan was emphasized. So too was good information channels and the social support of co-workers and supervisors.

\#MeToo has been called the biggest thing that has happened since women were given the right to vote. In Norway, the movement has breathed new life into the 22-year old ban on SH. There is no doubt, based on the backdrop of SH being illegal and a zero tolerance for this type of behavior in the media industry, that media houses and media organizations still have important work to do in this area. Thanks to the \#MeToo campaign, the issues of the $\mathrm{SH}$ of media workers and their coping strategies are now increasingly seen as structural problems and not just as individual level problems. This means that these issues can and must be reacted to at an organizational level, and be increasingly investigated in terms of what they indeed are: threats to the safety of journalists.

\section{Acknowledgments}

The authors would like to express their thanks to the Norwegian Fritt Ord Foundation and Rådet for Anvendt Medieforskning (the Norwegian Media Authority) for their financial support of important parts of this study.

\section{Conflict of Interests}

The authors declare no conflict of interests.

\section{References}

Act Relating to Equality and a Prohibition Against Discrimination, Norwegian Ministry of Culture $\S 13$ (2018). Retrieved from https://lovdata.no/dokument/NLE/ 
lov/2017-06-16-51

Association of Norwegian Editors. (2019). Årsmelding og regnskapp 2017-2018 [Annual report and finances 2017-2018]. Norsk Redaktørforening. Retrieved from https://www.nored.no/Redaktoernyheter/ Velkommen-til-NRs-landsmoete

Benavides-Espinoza, C., \& Cunningham, G. B. (2010). Bystanders' reactions to sexual harassment. Sex Roles: A Journal of Research, 63(3/4), 201-213.

Buchanan, N., Settles, I. H., Hall, A. T., \& O'Connor, R. (2014). A review of organizational strategies for reducing sexual harassment: Insights from the U.S. Military. Journal of Social Issues, 70(4), 687-702.

Carroll, L. (2013). Problem-focused coping. In M. D. Gellman \& J. R. Turner (Eds.), Encyclopedia of behavioral medicine (pp. 1540-1541). New York, NY: Springer.

Einarsen, S., \& Sørum, D. R. (1996). Arbeidskamerat eller sex-objekt? En krysskulturell studie av seksuell trakassering [Colleague or sex object? A crosscultural study of sexual harassment in the workplace]. Nordisk Sexologi, 14(1), 17-33.

Fitzgerald, L. F., Swan, S., \& Magley, V. J. (1997). But was it really sexual harassment? Legal, behavioral, and psychological definitions of the workplace victimization of women. In W. O'Donohue (Ed.), Sexual harassment: Theory, research, and treatment (pp. 5-28). Needham Heights, MA: Allyn \& Bacon.

Grimsmo, A., \& Heen, H. (2013). Journalistundersøkelsen 2012 [The journalist survey 2012]. Oslo: AFI/WRI.

Hagen, A. L. (2015). Meningers mot [The braveness of expressing an opinion]. Oslo: Cappelen Damm Akademiske.

Hogh, A., Mikkelsen, E. G., \& Hansen, Å. M. (2012). Impact of bullying on workers. In N. Tehrani (Ed.), Workplace bullying: Symptoms and solutions (pp. 21-34). East Sussex: Routledge.

Idås, T., \& Backholm, K. (in press). Seksuell trakassering $i$ norske redaksjoner [Sexual harassment in Norwegian newsrooms]. Manuscript submitted for publication.

Isdal, P. (2016). Smittet av vold: Om sekundærtraumatisering, compassion fatigue og utbrenthet $i$ hjelperyrkene [Infected by violence: About secondary traumatization, compassion fatigue and burnout among first responders and health care workers]. Bergen: Fagbokforlaget.

Kleppe, B., \& Røyseng, S. (2016). Sexual harassment in the Norwegian theatre world. The Journal of Arts Management Law and Society, 46(5), 282-296.

Matthiesen, S. B., \& Olsen, O. K. (2018). Seksuell trakassering i operative miljøer [Sexual harassment in the military]. Necesse 2018, 3(1), 58-69.

Nielsen, M. B., Bjørkelo, B., Notelaers, G., \& Einarsen, S. (2010). Sexual harassment: Prevalence, outcomes and gender differences assessed by three different estimation methods. Journal of Aggression Maltreatment \& Trauma, 19(3), 252-254.

Nielsen, M. B., \& Einarsen, S. (2012). Prospective relationships between workplace sexual harassment and psychological distress. Occupational Medicine, 62(3), 226-228.

Norwegian Audit Bureau of Circulations. (2019). Opplags: Og lesertall for 2018 andre halvår [Circulation and readership, second semester, 2018]. Norsk Opplagskontroll. Retrieved from https://www.opplag. no/opplagtall/opplagstall-2019-1

Norwegian Media Authority. (2019). Eigarskap i norske medium [Ownership in Norwegian media]. Medietilsynet. Retrieved from https://medietilsynet.no/ mediebildet/eierskap

Norwegian Union of Journalists. (2017). Hver tiende unge kvinne er seksuelt trakassert på jobb [Among young women, one out of ten is sexually harassed in the workplace]. Norsk Journalistlag. Retrieved from https://www.nj.no/nyheter/hver-tiende-ungekvinne-er-seksuelt-trakassert-pa-jobb

Norwegian Union of Journalists. (2018). 8019 NJere ved utgangen av 2017 [8019 NJ members at the end of 2017]. Norsk Journalistlag. Retrieved from https://www.nj.no/nyheter/8019-nj-ere-vedutgangen-av-2017

Orgeret, K. S., \& Vike Arnesen, M. (2019). The \#Metooposter. The \#Metoo-poster. Retrieved from https:// themetooposter.com

Rees, S., Simpson, L., McCormack, C. A., Moussa, B., \& Amanatidis, S. (2019). Believe \#metoo. Sexual violence and interpersonal disclosure experiences among women attending a sexual assault service in Australia: A mixed-methods study. BMJ Open, 9(7), e026773. http://dx.doi.org/10.1136/bmjopen-2018026773

Scarduzio, J. A., Sheff, S. E., \& Smith, M. (2018). Coping and sexual harassment: How victims cope across multiple settings. Archives of Sexual Behavior, 47(2), 327-340.

Sletteland, A., \& Helseth, A. (2018). Det jeg skulle sagt: Håndbok mot seksuell trakassering [What I should have said: A handbook in sexual harassment]. Oslo: Manifest.

Statistics Norway. (2019). Norsk mediebarometer [Norwegian media survey]. Statistisk Sentralbyrå. Retrieved from https://www.ssb.no/kultur-og-fritid/ statistikker/medie/aar

Vohlídalová, M. (2015). Coping strategies for sexual harassment in higher education: "An official action may harm you in the end more than if someone slaps your butt." Sociológia-Slovak Sociological Review, 47(3), 297-316.

Wexler, L., Robbennolt, J. K., \& Murphy, C. (2019). \#MeToo, time's up and theories of justice. Illinois Law Review, 2019(1), 45-110.

White, A. (2014, May 2). Fear in the news: The difference between self-censorship and ethical journalism. Ethical Journalism Network. Retrieved from https://ethicaljournalismnetwork.org/fear-inthe-news-the-difference-between-self-censorshipand-ethical-journalism 
Willness, C. R., Steel, P., \& Lee, K. (2007). A metaanalysis of the antecedents and consequences of workplace sexual harassment. Personnel Psychology, 60(1), 127-162.

Young, M. (2019, July 19). Online, workplace harassment add to dangers faced by female journalists. Voice of America News. Retrieved from https://www. voanews.com/press-freedom/online-workplaceharassment-add-dangers-faced-female-journalists

\section{About the Authors}

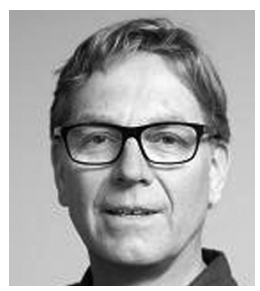

Trond Idås is an Adviser at the Norwegian Union of Journalists, specializing in the work environment, the safety of journalists, and media policies. He is currently pursuing a PhD at Åbo Akademi University (Finland) in post-traumatic stress among journalists.

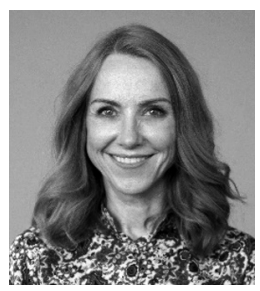

Kristin Skare Orgeret (PhD) is Professor at the Department of Journalism and Media Studies at Oslo Metropolitan University, Norway, where she co-heads the MEKK (Media, War and Conflict) research group. Her areas of research include conflict journalism, gender, and the safety of journalists.

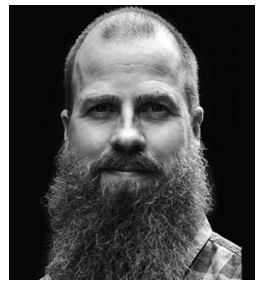

Klas Backholm (PhD) is a University Lecturer in Mass Communication, Political Science with Mass Communication, Åbo Akademi University (Finland). His research areas include: (a) the psychological wellbeing of journalists after work-related crisis exposure or harassment; and (b) best practices for crisis journalism and communication in the digital media landscape. 